\title{
Coupling effect of ozone column and atmospheric infrared sounder data reveal evidence of earthquake precursor phenomena of Bam earthquake, Iran
}

\begin{abstract}
Understanding the source mechanism of earthquakes may be the key to predict earthquakes. The testing of radioactive radiations and reactionary hypothesis of gases before and after quake events can help predict and monitor earthquake occurrence. In this study, the Atmospheric Infrared Sounder (AIRS) and the column ozone (O3) were applied to evaluate the December 26, 2003 earthquake of Bam city in western Iran. The results show that ozone concentration (column density) decreased about $30 \mathrm{DU}$ and or $807 \times 10 \mathrm{E} 15 / \mathrm{cm} 2$ molecules. Using high-resolution AIRS data for the study area, we were able to discriminate gases that formed and changed before the main shock at least a day before the occurrence of the quake in Bam.
\end{abstract}

Keyword: Earthquake precursor; AIRS; Remote sensing; GIS; Bam; Iran 